\title{
A GESTÃO DE CAMILLO DE HOLLANDA NA PARAHYBA (1916-1920): REDES DE SOCIABILIDADE E ATUAÇÃO POLÍTICA
}

\section{Ingrid Karla Cruz Biserra ${ }^{1}$}

Ao pensarmos sobre a estrutura e a organização política da Parahyba nas primeiras décadas republicanas, frequentemente nos deparamos com a figura do médico, coronel do exército e político Francisco Camillo de Hollanda. Seja destacando as ações em prol do embelezamento da cidade e da modernização urbana, ou como o presidente de estado que se preocupou com a construção de grupos escolares e que solicitou a elaboração da reforma da instrução pública, em 1917, treze anos após a última neste setor no estado. Fato é que na bibliografia que interpreta esse momento histórico, Camillo é lembrado como um homem ainda a ser investigado, em função, inclusive, do seu engajamento com um importante político de projeção nacional a época, Epitácio Pessoa. Isso chamou-nos a atenção. Assim, o objetivo desse texto é analisar alguns aspectos das redes de sociabilidade e da atuação de Camillo de Hollanda na Parahyba entre os anos de 1916 e 1920, período da vigência do seu mandato enquanto presidente do estado.

A análise das relações entre os sujeitos, estruturadas em redes de sociabilidade, isto é, em lugares de articulação, troca, contato e vínculo, além de situadas no tempo histórico dos sujeitos envolvidos, permite-nos entender traços específicos desses atores sociais. Consideramos que o olhar atento ao momento histórico, a estrutura, a organização do que se pretende analisar $e$ as relações entre os sujeitos pode trazer informações importantes sobre os grupos e os indivíduos, o que nos parece essencial, uma vez que são esses os sujeitos, homens e mulheres, atores do político, responsáveis pelas propostas e implementações que movimentaram e deram os rumos que desejavam ao estado da Parahyba.

Para Jean François Sirinelli ${ }^{2}$, o termo sociabilidade comporta duas acepções distintas, porém complementares: a primeira refere-se a noção de rede organizacional e a outra, a de microclima. Para o historiador francês, todo grupo de intelectuais se organiza a partir de uma sensibilidade ideológica ou cultural comum de afinidades que alimentam o desejo e o gosto de conviver. Esse encontro com um tipo de estrutura organizacional (uma espécie de rede) de sociabilidade, que varia conforme as épocas e os subgrupos de intelectuais, alimenta "microclimas" em meio aos quais as atividades e os comportamentos dos intelectuais se desenvolvem, constituindo microcosmos particulares. No âmbito dessas formulações, a proposta é dar especial

${ }^{1}$ Doutoranda no Programa de Pós-Graduação em Educação/ PPGE/ UFPB, na Linha de História da Educação. Professora mediadora no Curso de Especialização em Linguagem com Ênfase no Ensino de Língua Portuguesa (CLELP), da Universidade Federal da Paraíba (UAB/UFPB Virtual). É integrante do Grupo de Estudos e Pesquisas em História da Educação - GT Paraíba (HISTEDBR-PB), do Grupo de História da Educação do Nordeste Oitocentista (GHENO/CCHLA/UFPB) e do grupo História das Instituições e dos Intelectuais da Educação no Brasil, da PUC/ SP. Pesquisa financiada pela CAPES. Email: <ingridkarlacruz@gmail.com>.

2 SIRINELLI, Jean-François. "Os Intelectuais". In: RÉMOND, René (org.). Por uma história política. Tradução de Dora Rocha. Rio de Janeiro: Editora FGV, 2003. 
importância a alguns elementos que possam influenciar no funcionamento desse microcosmo, tais como demandas sociais, afetos e tradição.

A análise dos lugares de enunciação, a observação atenta às relações pessoais e as sensibilidades entre os sujeitos que se articulam, auxilia a entender as redes de sociabilidade.

A atração $e$ a amizade $e$, ao contrário, a hostilidade $e$ a rivalidade, a ruptura, a briga e o rancor desempenham igualmente um papel às vezes decisivo [...] de um lado, esse peso de afetividade adquire uma significação específica [...] de outro lado, a imbricação das tensões devidas aos debates de idéias e desses fatores afetivos desemboca talvez, em alguns casos, numa patologia do intelectual. ${ }^{3}$

As redes serão investigadas aqui a partir de algumas fontes: cartas enviadas por Epitácio Pessoa ${ }^{4}$ a Camillo de Hollanda, indicando como as relações pessoais estavam embrincadas nas relações políticas que eles estabeleceram. Esses fragmentos do vivido expressam dimensões do sujeito e podem auxiliar no entendimento de que "[...] as sociabilidades intelectuais não se esgotam no espaço público, mas comportam aspectos da vida privada em que se manifestam com clareza no jogo astucioso de ocultar/revelar da narrativa intencionalmente construída [...]" ${ }^{\prime 5}$; alguns livros sobre a História do estado, mensagens presidenciais, e a imprensa, por meio dos jornais $A$ União, Diário do Estado, A Notícia e O Imparcial. Cabe ressaltar que o trabalho com esses materiais nos estudos históricos passa pelo entendimento de que a imprensa participa da história, produz discursos, legitima e exclui outros, registra, comenta, ressalta, convence e forma opiniões. Os periódicos selecionam, ordenam os fatos, forjam discursos e mobilizam ideias. Por entre as linhas e impressões desses jornais foi possivel perceber nuances relacionadas as contendas políticas, as alianças $e$ as sociabilidades criadas e firmadas.

O artigo está organizado em duas seções. Na primeira, tratamos da organização política local que antecedeu a candidatura de Camillo de Hollanda, as redes que se firmaram para isso, principalmente com Epitácio Pessoa, e as repercussões da sua candidatura. Na segunda, abordamos as principais ações da sua gestão que, imbuída de um ideário modernizador, realizou várias mudanças no estado, especialmente no tocante ao remodelamento e ao embelezamento da cidade.

${ }^{3}$ SIRINELLI, "Os Intelectuais...", p. 250.

${ }^{4}$ Epitácio Lindolfo da Silva Pessoa (1865-1942) fez o ensino primário no Liceu Pernambucano, o secundário, no Ginásio Pernambucano, e diplomou-se em Direito pela Faculdade de Direito de Recife. Exerceu vários cargos, incluindo os de promotor, procurador, ministro da Justiça e negócios interiores, ministro do Supremo Tribunal Federal, secretário de governo, advogado, professor e jornalista. Na política, exerceu os seguintes mandatos: deputado (1891 a 1893), senador (1912 a 1919), presidente da República (1919 a 1922), e novamente senador (1924 a 1930).

${ }^{5}$ MALATIAN, Maria Teresa. "Cartas: narrador, registro e arquivo". In: PINSKY, Carla Bassanezi \& LUCA, Tania Regina de (orgs.). O historiador e suas fontes. São Paulo: Contexto, 2009, p. 210. 


\section{As redes de sociabilidade envoltas na candidatura a presidente do estado da Parahyba}

Francisco Camillo de Hollanda, o sexto filho do tenente-coronel Antônio Camillo de Hollanda e de Amalzide Meira Henrique, nasceu em 10 de setembro de 1862. Formou-se no Curso de Medicina da Faculdade da Bahia, em 1886, aos 24 anos, e defendeu a tese intitulada Considerações acerca das moléstias fetais que podem obstar o parto. Casou-se com Mariana Chaves Augusta de Hollanda e teve um único filho, Rafael de Hollanda.

Estudou na Escola de Aprendizes Marinheiros entre 1875 e 1879, exercendo também a função de médico civil. Ingressou no Exército brasileiro em 1889, como Tenente-cirurgião, e serviu ao $27^{\circ}$ Batalhão de Infantaria por dois anos. Hollanda fez parte do corpo de saúde do Exército durante 35 anos e foi nomeado Coronel em 1920. Em 1891, o personagem em questão foi transferido para a Província de Minas Gerais, para atuar no $31^{\circ}$ Batalhão de Infantaria, da guarnição de São João d'El Rei. Com a transferência desse batalhão para o Rio Grande do Sul, em 1893, ele foi novamente transferido, agora para a capital federal - Rio de Janeiro, com o objetivo de prestar serviços aos feridos da Revolta da Armada.

Acometido de beribéri, doença causada, principalmente, pela falta de vitamina B1 no organismo, recebeu licença para se tratar na Parahyba. Melhor de saúde, voltou a São João d'El Rei e logo foi escalado para fazer parte do grupo de médicos convocados para atender no interior da Bahia aos feridos da Guerra de Canudos. Chegando a Salvador, respondeu pela direção do Hospital Militar, uma vez que o diretor, Silvino Pacheco, estava em viagem ao interior da Província. Alguns dias depois, deslocou-se para Queimadas e, por sorte, não fez parte da expedição de Moreira César, em que todos foram dizimados. Finda a Campanha de Canudos, serviu à guarnição de Pernambuco e, em seguida, voltou para a Parahyba.

Adentrou a vida política, como deputado estadual pela Parahyba, entre os anos de 1900 e 1903. Nessa eleição para o cargo de deputado, acirraram-se as disputas entre os epitacistas e os alvaristas, no então governo do presidente de estado, Álvaro Pereira de Carvalho ${ }^{6}$, o que faria com que os epitacistas não tivessem oportunidade nesse pleito. No entanto, o Presidente da República, Campos Sales, convocou Epitácio Pessoa para o cargo de Ministro do Interior, e isso lhe deu mais vigor na política local. Essa aproximação de Epitácio Pessoa com Campos Sales colaborou para que o presidente decidisse as eleições ganhas pelos correligionários de Epitácio Pessoa. Camillo de Hollanda, partícipe da chapa Venâncio-Epitacista, foi eleito?

\footnotetext{
${ }^{6}$ Álvaro Pereira de Carvalho nasceu no município de Mamanguape (PB) em 1885. Formou-se pela Faculdade de Direito do Recife e foi professor do Liceu Paraibano. Em 1916 foi nomeado por Francisco Camillo de Hollanda, diretor do Liceu Paraibano. No governo de Sólon Barbosa de Lucena (1920-1924) assumiu o cargo de secretário-geral do estado. Em 1927 foi eleito deputado federal pela Paraíba para a legislatura 1927-1929. No entanto, renunciou ao mandato em 1928, pois foi eleito vicepresidente do estado na chapa de João Pessoa. Após a morte de João Pessoa, substituiu-o. Foi um dos fundadores da Academia Paraibana de Letras. Publicou algumas obras, como Revelações do eu (1920) e Ensaios da crítica (1924).

${ }^{7}$ ODILON, Marcus. Camillo de Hollanda: médico, militar e político. João Pessoa: Papel e Pano, $2^{\mathrm{a}}$ ed, 2001.
} 
Findo o mandato, serviu à guarnição do Pará e, em seguida, foi transferido para o Hospital Central do Exército, no Rio de Janeiro. Ainda prestou serviços à Força Expedicionária de Mato Grosso e, depois, em Pernambuco, com a patente de Major, no Hospital Militar. Posteriormente, foi nomeado Chefe do Serviço de Saúde do $4^{\circ}$ Distrito Militar em São Paulo. Novamente inserido na política, foi empossado no cargo de deputado federal em 1909 e em 1915. Nesse último mandato, Camillo de Hollanda renunciou por ocasião da candidatura a presidente do estado ${ }^{8}$.

Nesse momento, a política local era polarizada entre epitacistas e alvaristas. $\mathrm{O}$ primeiro era dividido em duas alas, os Goelas (epitacistas tradicionais) e os Jovens Turcos (epitacistas genuínos), que defendiam suas opiniões no jornal A Notícia e lançaram nesse periódico o nome do então deputado, Solon de Lucena ${ }^{9}$, à presidência do estado, em repulsa ao nome lançado pelos Goelas, Pedro da Cunha Pedrosa.

Os alvaristas apoiavam a candidatura de Álvaro Machado. Depois da sua morte, Monsenhor Walfredo Leal ${ }^{10}$ continuou a oposição aos epitacistas. Derrotado em 1915 por alianças políticas de Epitácio Pessoa, os walfredistas não se candidataram às eleições de 1916.

Em face do impasse quanto ao nome do candidato à presidência do estado, dentro do próprio partido liderado por Epitácio Pessoa, ele preferiu lançar um terceiro nome - o de Camillo de Hollanda. Epitácio escolheu Camillo por ser seu amigo e subordinado. Ele não queria alguém que pensasse diferente dele. Almejava um presidente para o estado que cumprisse suas ordens, embora tenha mudado de ideia depois. Esse posicionamento está ligado ao domínio político que Epitácio Pessoa exercia no estado durante o período, e "suas escolhas para governador entre 19121924 [...] refletiram sua forte preferência por candidatos leais e de trato fácil. Embora ele tenha errado nesses aspectos quando escolhe Camilo [...]"11. Ainda segundo esta autora,

Exceto durante o governo de Camilo de Holanda, entre 1916-1920, Epitácio tratou pessoalmente de todas as indicações para os cargos políticos estaduais e federais, assim como da escolha final dos prefeitos na Paraíba. Seus critérios de "lealdade" e "merecimento" mediam a capacidade de um chefe para proporcionar os votos locais por vários anos. ${ }^{12}$

8 RODRIGUES, Inês Caminha. A gangorra do poder (Paraíba - 1889/ 1930). Paraíba: Editora Universitária, 1989.

${ }^{9}$ Solon de Lucena exerceu as funções de professor na cidade de Bananeiras/ PB, secretário do estado e deputado federal no governo de Camillo de Hollanda. Assumiu o governo do estado duas vezes, a primeira em caráter emergencial em razão da renúncia de Antônio da Silva Pessoa, e a segunda quando eleito para os anos de 1920-1924. Implantou o Grupo Escolar de Campina Grande através do decreto de $\mathrm{n}^{\circ} .1 .317$ de 30 de setembro de 1924 e transformou a Lagoa dos Irerês em Parque Solon de Lucena, um dos principais cartões postais da capital da Paraíba atualmente.

${ }^{10}$ Walfredo Soares dos Santos Leal nasceu em Areia, em 1855, e faleceu em João Pessoa, em 1942. Sacerdote e político, exerceu vários cargos como os de deputado, vice-presidente, presidente e senador. Em sua homenagem, na capital, João Pessoa, há uma avenida com seu nome no Bairro de Tambiá.

${ }^{11}$ LEWIN, Linda. Política e parentela na Paraíba: um estudo de caso da oligarquia de base familiar. Rio de Janeiro: Record, 1993, p. 276.

${ }^{12}$ LEWIN, Política e parentela..., p. 285. 
Sobre o caráter de dominação exercido por Epitácio Pessoa nesse período, cabe destacar que estava atrelado, assim como ocorria em âmbito nacional, a um domínio oligárquico presente nas primeiras décadas da República, chamado de "política dos governadores", isto é, eram firmados acordos e alianças entre o Presidente da República e os governadores dos estados, a época chamados de presidentes de estado, estes que por sua vez exerciam autoridade entre correligionários e "afilhados" políticos.

De acordo com Gurjão que realizou um importante trabalho sobre as oligarquias no estado entre 1889 e 1945, "a estrutura de poder na Paraíba durante a Primeira República constituiu significativo exemplo do movimento de redefinição do mandonismo local e do apogeu da política oligárquica [...]"13. Funcionavam práticas de uma cultura política marcada pelo coronelismo, "sistema" político caracterizado pelas relações de amizade, compadrio, troca de favores, clientelismo, mandonismo $e$ barganha. A influência de Epitácio Pessoa era percebida, por exemplo, quando:

Ao se aproximarem as eleições, os chefes locais deviam escrever a Epitácio ou ao governador relatando as suas projeções relativas ao pleito, contendo estimativas aritméticas precisas de suas forças $e$ das forças oposicionistas, $e$ proporcionando uma avaliação do grau de violência esperado para o dia da eleição. ${ }^{14}$

Em face do domínio de Epitácio Pessoa na política do estado, as eleições eram momentos de agitação e expectativas quanto às sanções desse político. Nesse sentido, observamos que a predileção de Epitácio Pessoa por Camillo de Hollanda para presidir o estado não fora algo tão surpreendente. $\mathrm{O}$ jornal $O$ Imparcial, veiculado no Rio de Janeiro, capital Federal na época, em matéria de 1913 sobre os desejos e as manobras políticas de Epitácio Pessoa para implantar sua oligarquia na Parahyba, já lançava anúncios de uma possível candidatura de Camillo de Hollanda no lugar de Castro Pinto, presidente em exercício entre 1912-1915. De acordo com o jornal,

[...] esses movimentos do sr. Epitacio só tem um escopo: fazer seu o presidente do Estado da Parahyba [...] Já se fala que se o sr. Castro Pinto vier substituir o sr. Pedrosa, na renovação do terço, o seu substituto será o sr. Camillo de Hollanda, "enfant gaté" do sr. Epitacio. ${ }^{15}$

Camillo de Hollanda foi anunciado, por carta, da sua candidatura às eleições para o quadriênio 1916-1920. Tomou posse em 22 de outubro de 1916, juntamente com seu $1^{\circ}$ vice-presidente, Antônio Massa, e o $2^{\circ}$ vice-presidente, João Baptista Alves Pequeno, logo após desembarcar do Rio de Janeiro no dia 17 de outubro. Foi montada uma organizada estrutura para receber o novo presidente do estado nesse

${ }^{13}$ GURJÃO, Eliete de Queiróz. Morte e vida das Oligarquias - Paraíba (1889-1945). João Pessoa, Editora Universitária/ UFPB, 1994, p. 52.

${ }^{14}$ LEWIN, Política e parentela..., p. 278.

${ }^{15}$ O Imparcial. Rio de Janeiro, 02/11/1913. 
dia, como exposto em matéria de A Notícia, intitulada Dr. Camillo de Hollanda, em 17/09/1916. Segundo o jornal, foram estabelecidas as seguintes comissões: comissão central de organização geral das festas, comissão de recepção no Recife, comissão de recepção nessa capital, comissão do banquete, comissão do baile e comissão de ornamentação de ruas.

Alguns dias antes da sua posse, A Notícia, periódico ligado a ala epitacista, publicou uma matéria reafirmando a organização elaborada para receber o novo presidente do estado e expôs a sua simpatia por ele, dando boas vindas a Camillo de Hollanda.

O partido dominante organizou, a fim de receber o egregio patrício, festas ruidosas, bastante significativas para traduzir a consideração que a s. exc. deve o povo da Parahyba. O ilustre concidadão ja de ha muito possuia nessa sociedade um circulo vasto de affeições pessoaes e politicas, sendo incontestavelmente um dos nossos prestimosos e festejados homens publicos. [...] O programma de s. exc. está na linha dessa doutrina fidalga e superior da democracia. Dentro delle, o sr. Camillo de Hollanda pode ser, e fiamos que o será, o ponto de equilíbrio da nossa harmonia, a segurança da ordem e progresso da Parahyba, no quadriênio que se approxima. [...] Recebendo com estima, sympathia e fundo respeito a novo presidente, adiantamos a s. exc. as nossas cordiaes saudações. ${ }^{16}$

A oposição, representada agora pelos walfredistas, manteve em circulação o Jornal Diário do Estado, que apresentava, entre outras coisas, críticas ao governo situacionista, como a que expomos abaixo:

Duas linhas parallelas por mais que se prolonguem não se encontram. São assim os governos de Venancio Neiva que acabou disposto por ser o primeiro na Republica, e o de Camillo de Hollanda, que há de ser o ultimo, embora mal comece. [...] Venâncio foi a Republica, fêz governo de todos para todos, e por todos, procurando ensaiar o regime. Camillo de Hollanda vai ser o epilogo. O primeiro tiha responsabilidade, governou por si [...] O segundo, se é ainda cêdo para julgal-o [...] Não é um mandante, cumpre ordens em lugar de dal-as, porque o seu secretario é quem vai fazer a politica. [...] Venancio e Camillo são parallelos que não se encontram, salvo se formarem um ângulo nullo na Republica. ${ }^{17}$

\footnotetext{
${ }^{16}$ A Notícia. Parahyba, 17/10/1916, p. 01.

${ }^{17}$ Diário do Estado. Parahyba, 20/01/1917, p. 02.
} 
Próximo às eleições em que Camillo de Hollanda seria eleito presidente do estado, ele enviou um telegrama ao jornal A União, que fora reproduzido no jornal A Notícia, em $1^{\circ}$ de julho de 1916 . O futuro presidente agradecia aos amigos da redação do jornal que enviaram saudações e apoio, $e$ apontou que as intrigas da oposição não o abalariam. Cabe ressaltar que o jornal A União era o jornal oficial do governo do estado da Paraíba a época, publicava os atos e enaltecia os feitos de alguns representantes.

[...] Aproveito a opportunidade para manifestar á $<\mathrm{A}$ União> o meu reconhecimento pela defesa feita á minha candidatura, como para assegurar publicamente não me impressionarem as intrigas de adversarios, que procuram pôr em duvida a sinceridade de alguns correligionarios á minha candidatura. Não será por taes processos, nem pela malsinação ao meu dilecto amigo e chefe, senador Epitacio Pessôa, e coronel Antonio Pessôa, com cujos actos sou inteiramente solidario, que lograrõa chegar até mim. Saudações cordiais - Camillo de Hollanda. ${ }^{18}$

Embora, na maioria das vezes, o partido de oposição atacasse, também teceu elogios a algumas ações do governo. Em setembro de 1917 o jornal Diário do Estado publicou:

[...] Homem operoso, intelligente, dispondo de capacidade administrativa, pouco commum para guiar a náu do Estado. $\mathrm{S}$. Excia. Em menos de um anno de governo, tem realizado melhoramentos materiaes sorprehendentes em nossa capital; tem se interessado grandemente pela instrucção publica e ha recebido sempre com carinho reclamações de certa monta [...] Deixemos de lado as questões meramente partidarias, nós hoje apreciamos somente o administrador. [...] Adversarios, nem por isso, deixemos de o aplaudir, uma administração honrada e operosa [...]. ${ }^{19}$

Parecia estranho um jornal de cunho oposicionista, criado em 1915, especificamente para esse fim, publicar elogios ao presidente de estado do partido contrário. Assim escreve Epitácio Pessoa, em uma de suas cartas enviadas a Camillo de Hollanda. Para o chefe do partido epitacista, também soava curioso o fato de o jornal A União não responder às críticas feitas ao governo, como exposto em carta para o presidente do estado. Segundo Epitácio Pessoa,

[...] o que é certo é que a atitude da UNIÃO, órgão do Partido, em face do DIÁRIO, não tem explicação. É singular que a fôlha oposicionista ataque, injurie, calunie diàriamente

\footnotetext{
${ }^{18}$ HOLLANDA, Camillo. Telegrama enviado ao Jornal A União, reproduzido pelo Jornal A Notícia, em $1^{\circ}$ de julho de 1916, sob o título Um telegramma do Dr. Camillo de Hollanda à A União.

${ }^{19}$ Diário do Estado. Parahyba, 11/09/1917, p. 01.
} 
o Partido e seu chefe e o órgõa do Partido se conserve silencioso, porque... a dita fôlha elogia o Presidente do Estado! Que significa isto? Incompetência?! Pusilanimidade?! Inépcia?! Acôrdo entre os dois?! São as perguntas que recebo de vários pontos do Estado [...]. ${ }^{20}$

Que o jornal A União publicava elogios, isso já estava explícito e implícito, mas o Diário do Estado publicar notícias favoráveis ao governo parecia acordo ou alianças entre seus dirigentes e o próprio governo local. Talvez fosse isto ou não. O fato é que essas notícias elogiosas a Camillo de Hollanda no Diário do Estado começou a intrigar Epitácio Pessoa e gerou desconfianças com relação a algumas atitudes de Hollanda.

Sobre as relações de Camillo de Hollanda com o Jornal A União, percebemos que Carlos Dias Fernandes ${ }^{21}$, responsável pela direção desse periódico tinha uma ótima relação com o presidente do estado. Ambos teciam elogios um ao outro, e Dias Fernandes permaneceu no cargo de diretor da imprensa oficial durante todo o governo de Camillo de Hollanda, que mandou adotar, via decreto, um livro de Dias Fernandes nas escolas primárias do estado. Em 1918 o decreto n. 913 de 14 de março, instituiu a adoção do livro Escola Pittoresca, produzido e escrito por Dias Fernandes.

A boa relação entre os dois estava explícita nos meios que dispunham para isso. $\mathrm{O}$ intelectual Carlos Dias Fernandes faz alguns elogios ao governo e a Camillo de Hollanda no Almanack do Estado da Parahyba, em 1918. Segundo esse personagem paraibano,

[...] Quando forem transactas essas actualidades que agora celebramos e chegar o momento da apreciação historica desse govêrno, dir-se-á delle que foi justo, laborioso e honrado, fazendo-se, pois, o mais alto elogio ao cidadão simples, estoico e modesto em que a Parahyba já reconhece agradecida um dos seus mais nobres filhos, exornado com todos os requisitos do homem de Estado por excellencia. ${ }^{22}$

Nesse mesmo almanaque de 1918, foi publicado o hino em comemoração ao centenário da Revolução Republicana de 1817, cuja letra é de Carlos Dias Fernandes. Percebe-se que as relações entre ele e o governo, na figura de Camillo de Hollanda, eram estreitas, e no campo em que atuavam, concediam espaços um para o outro, corroborando a política da amizade e de compadrio que favorecesse os interesses de cada um.

${ }^{20}$ PESSOA, Epitácio. Obras completas de Epitácio Pessoa. Rio de Janeiro: Ministério da Educação e Cultura, 1962, p. 285.

${ }^{21}$ Carlos Dias Fernandes nasceu em Mamanguape, em 1874, e faleceu na cidade do Rio de Janeiro em 1942. Foi escritor, jornalista, bacharel em Direito, escritor em A Imprensa, diretor do jornal A União (1913-1925). Algumas de suas obras são: Conferência Noção de Pátria (1914), Proteção aos animais (1914); Os Cangaceiros (1914), A Defesa Nacional (1916); Livro infantil Escola Pittoresca (1918), Infância Proletária (1924), O Problema da instrucção pública no Brasil (1924).

${ }^{22}$ PARAHYBA, Estado da. Almanach do Estado da Parahyba. Imprensa Oficial, Parahyba: 1918, ano 12, 179-181. 
Em contrapartida, aos poucos, a relação entre Camillo de Hollanda e Epitácio Pessoa se modificava. O primeiro não cedia às imposições de Epitácio Pessoa e deixava-o insatisfeito. Inês Caminha Rodrigues, em seu livro, A gangorra do Poder (Paraíba - 1889/ 1930), traz algumas das contendas políticas que estremeceram a relação entre os dois políticos. Faz isso por meio de correspondências - cartas e telegramas, trocadas por ambos e entre os seus correligionários. Algumas dessas correspondências encontram-se na coleção de Obras completas de Epitácio Pessoa, organizada pelo Instituto Nacional do Livro, em parceria com o Ministério da Educação e Cultura em 1962. Apresentamos, abaixo, o trecho de um telegrama de Epitácio Pessoa para o chefe do governo estadual, em que fica evidente o descontentamento do primeiro em relação aos atos realizados pelo então presidente de estado e amigo:

Acabo saber surprêsa Órris nomeado fiscal Liceu, nomeação federal eu oferecera $V$. recusara e agora é feita seu pedido minha revelia. [...] É quarta vez V. desautorisa minha palavra. Não posso dissimular meu sentimento, sobretudo quando recordo nossa amizade, suas declarações aqui. Já tenho mêdo notícias Paraíba, por quanto depois meu melhor amigo assumiu Govêrno, quase nada mais faço que reclamar contra atos seus $[\ldots] .^{23}$

Numa longa carta enviada a Camillo de Hollanda, o presidente do Partido Republicano, Epitácio Pessoa, envolto nos sentimentos de amizade de mais de 30 anos e da aliança política entre ambos, aponta algumas ações oficiais que não lhe agradaram e o quanto isso mexeu com a relação que tinha com Camillo de Hollanda, embora ainda tenha afirmado a estima que tinha por esse.

Camilo. Nessa carta vou lhe falar com a franqueza que é um dever entre amigos como nós. Antes de apresentada a sua candidatura, $\mathrm{V}$. dizia sempre que se fôsse presidente, os seus auxiliares de Govêrno seriam indicados por mim. [...] Eu estava certo de sua sinceridade, não só porque não tinha o direito de duvidar dela, mas ainda porque as cousas deviam ser assim mesmo: os auxiliares de direção nunca foram de confiança pessoal do presidente, mas da confiança política do partido. [...] Era essa a minha convicção [...] Qualquer porém que seja a causa dessa transformação, peço-lhe, em bem da nossa amizade, que me dê explicações dos fatos que acabo de apontar/ peço-lhe que me diga com franqueza se quer ou não a minha solidariedade [...]. ${ }^{24}$

Desde o início do mandato, Camillo de Hollanda contrariou as expectativas de Epitácio Pessoa. Um dos aspectos se refere a composição do grupo que faria parte do

\footnotetext{
${ }^{23}$ PESSOA, Obras completas..., p. 261.

${ }^{24}$ PESSOA, Obras completas..., p. 256-270.
} 
governo. O chefe do partido esperava que suas indicações fossem colocadas em prática, pautando-se na política patrimonialista e de patronagem, todavia, Camillo optou pelos seus sobrinhos e o seu grupo familiar, em detrimento aos de Epitácio. Além disso, a remodelação dispendiosa realizada por Camillo de Hollanda gerou aborrecimentos.

Intrigas que envolviam Solon de Lucena e Camillo de Hollanda também colocavam Epitácio Pessoa num complicado impasse político-partidário. Para este último, a saída estava em convidar Camillo de Hollanda para o Senado. Assim o fez, mas ele recusou. Epitácio Pessoa então deslocou Solon de Lucena para a Câmara Federal, o que acalmou mais os ânimos entre os dois envolvidos.

Toda essa movimentação fazia parte do jogo político da época. Percebemos que, ao relatar as ideias e os posicionamentos de determinados sujeitos, a opinião pessoal $e$ política de alguns personagens engajados no debate público ficam evidentes e constroem as redes de sociabilidade presentes em tais relações. São essas redes que tecem as tramas de uma sociedade e que estão presentes nas ações dos sujeitos nos espaços que participam. Interessa-nos agora pensar sobre como foi a gestão de Camillo de Hollanda em meio a essas redes que se formaram. É o que abordaremos na seção seguinte.

\section{A gestão de Camillo de Hollanda na presidência do estado: em busca do remodelamento e embelezamento da cidade}

Imbuído do discurso de modernidade da época, o governo de Camillo de Hollanda (1916-1920), na Parahyba, desenvolveu uma proposta de higienização e embelezamento, presente nas leis municipais em relação ao espaço urbano. As edificações particulares foram se adaptando ao novo espaço urbano que se formava. Cabe destacar que essas iniciativas são decorrentes de um longo debate iniciado no século XIX, muito em razão da ascensão da medicina social patrocinada pelo Estado, que buscava adequar a cidade às condições sanitárias, de saúde e de beleza. Era um período em que várias doenças assolavam o país, como a cólera e a tuberculose, e o ideário higienista aos poucos foi se consolidando e ganhando representatividade no espaço público, que teve de ser reorganizado.

$\mathrm{Na}$ esteira de um movimento de remodelação dos espaços de moradia, lazer $e$ trabalho, desde o início do século XX, os governos na Parahyba, a fim de transformar os espaços públicos e os lugares higiênicos, arborizados e que elucidassem ares modernos, aos poucos, transformaram o ambiente urbano. Atreladas à modernização urbana, estavam os ideais sanitaristas seguindo um movimento nacional. Os saberes médico-higienistas fizeram-se presentes nas ações durante o governo de Camillo de Hollanda. Empreendidas a partir das questões ligadas à saúde, as transformações urbanísticas e institucionais refletiam essa orientação.

Camillo fora médico, antes de administrar o estado, e de acordo com Castro, "quem estudar a história dos movimentos políticos, ha de encontrar, com frequência, o nome de nossos médicos antigos, em posição de destaque, ou jogados ao 
ostracismo" 25 . Segundo Guedes, "sua disciplina e consciência sanitarista, adquiridas na formação militar e médica, essa pela Faculdade de Medicina da Bahia, certamente o auxiliaram na administração pública do Estado"26. Essa é uma visão com a qual Silva Filho ${ }^{27}$ também concorda, quando afirma que o fato de Camillo de Hollanda ser general e médico tem intrínseca relação com as suas ações governamentais voltadas para a saúde. Um exemplo de tais atuações são as primeiras discussões sobre a criação do Hospital-colônia Juliano Moreira, hoje chamado de Complexo Psiquiátrico Juliano Moreira, na capital. Embora iniciadas pelo presidente anterior, João Pereira de Castro Pinto, foi no governo de Camillo de Hollanda que as coisas pareciam se tornar mais concretas, ainda que não efetivadas no sentido da construção do hospital, que só foi inaugurado em 23 de junho de 1928, no governo de João Suassuna (1924-1928).

A história hospitalar da Psiquiatria, no estado, remonta a meados de 1890 , no governo de Venâncio Neiva (1889-1891), quando o Asylo de Sant' Anna foi instalado. Em meio às críticas a essa instituição, aos poucos, os médicos e os políticos foram discutindo sobre as propostas de se criar um hospital voltado para o tratamento dos que precisavam de ajuda psiquiátrica. Essa preocupação também esteve presente no governo de Camillo de Hollanda:

Em meados de 1917, o governo do Estado enviou a cidade do Rio de Janeiro (RJ), o Psiquiatra paraibano Dr. Octávio Ferreira Soares para melhor estudar uma assistência especializada e condigna aos pacientes psiquiátricos, esse contou com a ajuda e incentivo do Dr. Waldomiro Pires Ferreira (conterrâneo da Paraíba), junto ao consagrado Psiquiatra baiano Dr. Juliano Moreira (na época o maior nome da psiquiatria brasileira), que sensibilizado enviou uma "planta" do Hospital nacional dos Alienados (Rio de Janeiro - RJ) para servir de modelo ao futuro Hospital Psiquiátrico da Paraíba [...]. ${ }^{28}$

O Imparcial também trouxe uma notícia sobre o fato, ao afirmar, em uma de suas seções, que Camillo de Hollanda, "[...] pretendendo reformar o Hospicio de Alienados, por ser o actual inadequado aos seus fins, solicitou do dr. Juliano Moreira, conselhos technicos para levar a effeito a sua deliberação"29.

Segundo o próprio chefe do governo estadual, "outro ponto da administração que me merece cuidados especiaes, no meu duplo caracter de medico e administrador, é

${ }^{25}$ CASTRO, Oscar Oliveira. Medicina na Paraíba: flagrantes de sua evolução. João Pessoa: A União, 1945, p. 221.

${ }^{26}$ GUEDES, Kaline Abrantes. O ouro branco abre caminhos: o algodão e a modernização do espaço urbano da cidade da Parahyba (1850-1924). Dissertação (Mestrado em Arquitetura e Urbanismo). Universidade Federal do Rio Grande do Norte. Natal, 2006, p. 120.

${ }^{27}$ SILVA FILHO, Edvaldo Brilhante da. História da Psiquiatria na Paraíba. João Pessoa: Santa Clara, 1998.

${ }^{28}$ SILVA FILHO, História da Psiquiatria..., p. 70.

${ }^{29}$ O Imparcial. Rio de Janeiro, 20/05/1917, p. 02. 
a hygiene publica"30. Como uma ação para buscar precauções contra certas enfermidades, Camillo de Hollanda, por meio do decreto n. 953, de 16 de junho de 1918, criou um serviço de profilaxia, e em 1919, foi realizada uma ação preventiva, em que "[...] uma commissão de polícia sanitaria a serviço do govêrno federal, foi incumbida da prophylaxia da febre amarella. Essa commissão chefiada pelo illustre Dr. Vital de Mello essa prestando relevantes serviços a Capital [...]" ${ }^{\prime 1}$.

Camillo de Hollanda expressava em seu discurso que a falta de higiene acarretava doenças e, como consequência, aumentaria a taxa de mortalidade. Em mensagem de 1918, afirma que a mortalidade infantil aumentava no estado, e uma das providências seria criar um laboratório de análises clínicas e melhorar o serviço de profilaxia. Segundo o presidente de estado, "sanear as cidades e sanear os campos é hoje o maior problema econômico do Brasil. Nesse sentido, a Parahyba precisa fazer alguma cousa [...]"32. Esse serviço era necessário, porque havia "[...] numero considerável de pequenos pantanos tornando inhospitas certas regiões. Providenciar contra todos será desejo irrealizavel, mas desseccar ou drenar convenientemente o maior numero possivel, constitue por si só nobre, fecundo, generoso programma $[\ldots]]^{33}$.

O jornal A União, em sua edição de 8 de julho de 1917, aborda a conferência que fora realizada no Rio de Janeiro, sob a organização do médico Belisário Penna, que tratou do tema da higiene dos campos. Segundo o jornal, assim como as ideias de Belisário Penna, o governo estadual tem empreendido visitas aos municípios a fim de observar e melhorar suas condições higiênicas. A partir delas, observou que muito precisava ser melhorado para evitar doenças, uma vez que o verão se aproximava $e$, com ele, várias doenças típicas desse clima, como o sarampo e a bexiga, poderiam aflorar.

Duplamente investido em deveres que lhe assistem como clinico e chefe do Estado, o sr. Dr. Camillo de Hollanda preoccupa-se muito do nosso problema hygienico, que é um dos que nos pedem mais completa e inadiavel solução. [...] Do que tem visto e notado infere o sr. presidente que ha muita facilidade e negligencia nos nossos habitos caseiros em parte incrementada pela tolerancia dos inspetores de Hygiene. Estamos em fins de inverno: habitamos uma cidade de fossas fixas, onde os detrictos e as materias escrementicias em decomposição exhalam gazes toxicos que infeccionam o ambiente. Já nos espreitam as molestias zymoticas contagiosas, que fazem a sua eclosão costumada nos calores do estio. Urge-nos, pois, a nós, habitantes da capital e aos

\footnotetext{
${ }^{30}$ PARAHYBA, Estado da. Mensagem apresentada à Assembléia Legislativa na abertura da $2^{a}$ sessão ordinária da $8^{a}$ legislatura, pelo Francisco Camillo de Hollanda (presidente do estado) em $1^{\circ}$ de setembro de 1917. Parahyba: Imprensa Official, 1917, p. 09.

${ }^{31}$ PARAHYBA, Estado da. Mensagem apresentada à Assembléia Legislativa na abertura da $4^{a}$ sessão ordinária da $9^{a}$ legislatura, pelo Francisco Camillo de Hollanda (presidente do estado) em $1^{\circ}$ de setembro de 1919. Parahyba: Imprensa Official, 1919, p. 13.

${ }^{32}$ PARAHYBA, Mensagem apresentada..., p. 22.

${ }^{33}$ PARAHYBA, Mensagem apresentada..., p. 23.
} 
medicos zeladores da Hygiene Publica, estar em guarda permanente contra o inimigo ameaçador. ${ }^{34}$

Essa preocupação higiênica atrelada à cidade que reverberaria na saúde dos sujeitos, foi percebida no discurso dos jornais do período e também nos debates parlamentares. A necessidade de mudanças do ponto de vista sanitarista estava atrelada também as questões de natureza estética, em que figuravam as ações de embelezamento da cidade. Na Assembleia Legislativa do estado da Parahyba, esse aspecto, característico do seu governo, também foi retratado entre os parlamentares, como observado no discurso de Seraphico Nobrega ${ }^{35}$, presente na ata da $52^{\mathrm{a}}$ sessão, da $25^{\text {a }}$ reunião da $7^{\text {a }}$ legislatura, em 30 de outubro de 1916, em que o deputado afirma a necessidade de melhoramentos em diversos pontos da capital, uma vez que as ruas da cidade estavam esburacadas, desalinhadas, caracterizando-as como verdadeiros pardieiros. Para o deputado, "o Sr. Dr. Camillo de Hollanda, viajado e conhecedor das grandes cidades do Brasil e da Europa, deve, agora que é governo, se interessar pelo embellesamento e pelos melhoramentos de que essa capital precisa urgentemente" 36 .

Dentro desse plano urbanístico, foram construídas algumas praças na cidade, tendo em vista que "um programma de remodelação da capital não podia desprezar os diversos trechos da cidade que se prestavam para logradouros públicos. Assim, voltamo-nos para a construçcão de praças publicas, tão indispensáveis à vida das populações" ${ }^{\prime 7}$. São elas: as praças Aristides Lobo - onde foi colocado o primeiro monumento público da cidade, em homenagem a Aristides Lobo, encomendado por Castro Pinto; Pedro Américo, que também contou com um monumento do pintor; Conselheiro Henriques; Rio Branco e Bella Vista. Também foram feitos melhoramentos na Praça Venâncio Neiva, atualmente conhecida em João Pessoa como Pavilhão do Chá. Esses melhoramentos buscavam a modernização da cidade e contavam com a contribuição de arquitetos renomados, como Fiorilo, Di Lascio, Olavo Freire e Clodoaldo Gouveia, que introduziram elementos decorativos representados pela art nouveau.

As vias públicas foram modificadas, a fim de "[...] facilitar o transito de sua população, corregindo, ao mesmo tempo quanto possível, os defeitos de alinhamentos e construcção das ruas existentes" ${ }^{38}$. Foram abertas as Avenidas São Paulo, General Osório, Maximiano de Figueiredo, Epitácio Pessoa, reformadas as Ruas Maciel Pinheiro, Amaro Coutinho, Rosário, da República, Irineu Joffylli e a Avenida Beaurepaire Rohan, além do alargamento da Avenida Cruz das Almas. Também foi ampliada a rede de iluminação e abastecimento d'água e reconstruída a ponte sobre o Rio Sanhauá.

\footnotetext{
${ }^{34}$ A União. Parahyba, 08/07/1917, p. 01.

${ }^{35}$ Seraphico Nóbrega (1863-1935) foi advogado, professor, deputado estadual, federal e sócio fundador do Instituto Histórico e Geográfico Paraibano.

${ }^{36}$ NÓBREGA, Seráfico da. Ata da $52^{a}$ sessão da $25^{a}$ reunião da $7^{a}$ legislatura, em 30 de outubro de 1916. Parahyba, 1916, p. 51.

37 PARAHYBA, Estado da. Exposição de motivos e ocorrências do quadriênio administrativo pelo Francisco Camillo de Hollanda ao presidente do estado, Solon de Lucena, em 22 de outubro de 1920. Parahyba: Imprensa Official, 1920, p. 17.

${ }^{38}$ PARAHYBA, Exposição..., p. 18.
} 
Outro aspecto importante foi a mudança dos nomes das ruas, das avenidas e dos logradouros públicos da cidade. Durante o governo de Camillo de Hollanda, algumas ruas antigas, antes chamadas de Melão, Portinho e Areia, passaram a se chamar Beaurepaire Rohan, Amaro Coutinho e Barão da Passagem, respectivamente. Os nomes de personalidades do estado foram usados para denominar os caminhos da cidade que se transformava.

Sobre a questão acima, vale ressaltar que essa característica vista no governo de Francisco Camillo de Hollanda faz parte de um movimento nacional mais amplo que se instalava com a República. A invenção de uma tradição republicana fez surgirem vários elementos para legitimá-la, como hinos, bandeira e heróis. Buscavam-se os construtores da nação, aqueles que tinham o poder de organizá-la, e os intelectuais da época, indissociados da política, faziam parte desse segmento. Abrir caminhos e neles colocar o nome de homens ilustres fazia parte da tradição que a República queria deixar como legado.

No interior do estado, também foram realizados alguns melhoramentos, como a construção do reservatório de água no município de Esperança, e feito o saneamento da cidade de Alagoinha. Em setembro de 1918, o governo de Camillo de Hollanda promoveu, na capital, um Congresso de Prefeitos, em conjunto com a Sociedade de Agricultura da Parahyba. Entre outros assuntos, discutiu-se sobre os orçamentos municipais e a organização da caixa agrícola.

Sobre o governo e as obras empreendidas na gestão de Camillo de Hollanda, "as obras por ele realizadas tiveram a característica de terem sido produzidas por arquitetos e engenheiros treinados no exterior e na capital brasileira" ${ }^{39}$. A maioria desses arquitetos, assim como Hermenegildo Di Lascio, era formada em Paris, cidade com modelo arquitetônico a ser seguido. A capital federal, então, Rio de Janeiro, também imbuída desse ideário, iniciou, nas primeiras décadas da República, um processo de urbanização e de embelezamento, que fora seguido por várias capitais brasileiras, como sinônimo de progresso, higiene e modernidade.

$\mathrm{Na}$ Parahyba, tais obras eram coordenadas pelo diretor de obras públicas, Raphael de Hollanda, filho do presidente de estado, e faziam parte de um plano de embelezamento da cidade, com prédios modernos dotados de boas condições higiênicas, praças, vias de acesso alargadas, enfim, obras arquitetônicas que, segundo o discurso oficial do governo, diminuíram o ritmo em razão de uma crise financeira ocorrida em 1919.

Ressaltamos, no entanto, que seu governo não foi marcado apenas por elogios. $\mathrm{O}$ historiador Osvaldo Trigueiro de Albuquerque e Melo ${ }^{40}$, de acordo com Odilon, denominou o governo de Camillo de Hollanda como o Governo do Racha, sentido figurado dado em referência à suposta má qualidade das obras empreendidas pelo presidente. Odilon não só discordou de Trigueiro, como também explicou o motivo do seu depoimento:

${ }^{39}$ ARAÚJO, Darlene Karla. O impacto da nova arquitetura pública na paisagem da capital paraibana: 1900-1950. Dissertação (Mestrado em Engenharia urbana). Universidade Federal da Paraíba. João Pessoa, 2008, p. 27.

${ }^{40}$ TRIGUEIRO, Osvaldo. A Paraíba na Primeira República. João Pessoa: A União, 1982. 
[...] só depois de pesquisar durante algumas semanas, percebi o porquê da oposição de Trigueiro. Um dos primeiros atos de Camillo de Hollanda, como Governador, foi demitir da Prefeitura de Alagoa Grande [...] o coronel da Guarda Nacional Francisco Luiz de Albuquerque e Mello, substituindo-o por Félix Guerra, dono de um curtume. $\mathrm{O}$ coronel demitido era genitor de Trigueiro [...]. ${ }^{41}$

De acordo com Guedes, sobre a denominação de Trigueiro ao Governo de Camillo de Hollanda, "as obras de seu governo não eram de má qualidade. Questionava-se, todavia, a grande soma de recursos gastos nessas obras [...] que consumisse tamanha soma de dinheiro público" ${ }^{42}$. Crítica similar a essa foi a realizada por Celso Mariz, que caracterizou a administração de Camillo de Hollanda como dispendiosa. Todavia, esse autor também expõe sobre o quanto sua gestão trouxe benefícios para o estado. Segundo Mariz,

O Dr. Camilo fez uma política feia e confusa entre todos os elementos militantes, mas conseguiu tirar o governo com muito apoio e prestígio, mantendo até o fim o espírito ativo, desdenhoso e autoritário que se revelou. Sua administração, se bem que acusadíssima de esbanjamentos e concessões rendosas, ficou como um surto da Paraíba para a vida do progresso novo. Coincidiu a posse do Dr, Camilo de Holanda com a alta dos nossos produtos, sobretudo do algodão que as fábricas do sul rogavam, no retraimento da indústria estrangeira absorvida pela chamada de conflagração europeia. [...] Pôde, pois, esse administrador realizar serviços notáveis, sendo certo que fomentou a agricultura e renovou a cidade, ficando, sob o aspecto dos melhoramentos materiais, com as avenidas, praças e edifícios que contribuiu, ao lado dos maiores realizadores do nosso governo, ao lado de Beaurepaire Rohan (1859), Felizardo Toscano (1865) e João Lopes Machado (1908-1912). ${ }^{43}$

Como foi visto, o governo de Camillo de Hollanda é tratado, nos textos sobre a história da Paraíba e na bibliografia recente citada, como aquele que operou investimentos em diversos setores públicos e remodelou a capital paraibana aos ares modernos. No conjunto de autores/as que consultamos e abordaram o governo de Camillo de Hollanda, apenas Trigueiro ${ }^{44}$ apontou críticas, denominando-o de "Governo do Racha", em alusão à suposta má qualidade de suas obras urbanísticas. Os pares do presidente de estado, na época, teceram elogios a ele e a sua administração. A maioria deles eram amigos de partido e favorecidos em cargos

${ }^{41}$ ODILON, Camillo de Hollanda..., p. 52.

${ }^{42}$ GUEDES, $O$ ouro branco..., p. 128.

${ }^{43}$ MARIZ, Celso. Apanhados Históricos da Paraíba. João Pessoa: A União, 1994, p. 199-200.

${ }^{44}$ TRIGUEIRO, A Paraíba... 
públicos ligados ao estado. Aqui talvez esteja implícita a razão de tantas características elogiosas feitas ao chefe do governo estadual. Imbricavam-se as relações de amizade e de compadrio, e as redes, muitas vezes, estabeleciam-se em razão disso.

Segundo Odilon, Camillo de Hollanda, em 1930, foi novamente convidado a pleitear o cargo de deputado federal pelo Partido Republicano Conservador. Todavia, pouco antes do pleito, foi substituído por João Suassuna, e "[...] pela segunda vez, Camillo de Hollanda foi cortado da chapa. Mas, ao que parece, com seu próprio consentimento, a fim de permitir fortalecer o partido, do qual participava há dez anos" 45 .

Não se engajou mais na política. Após o seu falecimento, em 1946, como homenagem póstuma, foi implantado nas Trincheiras o busto de Camillo de Hollanda, feito pelo artista pernambucano, Bibiano Silva, no governo do Prefeito Oswaldo Pessoa (1947-1951), além do nome de uma avenida da cidade de João Pessoa. No município de Cajazeiras/ Paraíba, também há uma praça com o nome do personagem.

Camillo de Hollanda ainda é um sujeito que precisa ser investigado sob diversos ângulos. Aqui destacamos alguns elementos ligados às relações que foram estabelecidas entre os sujeitos partícipes da trama política enquanto fora presidente do estado, mas nos parece interessante objeto também debruçar-se com outros enfoques sobre a atuação deste sujeito que fora médico, coronel e figurou na política durante alguns anos, estabelecendo, inclusive, relações estreitas com figuras de altos cargos políticos em âmbito nacional. Perceber como foram os seus mandatos enquanto deputado pela Paraíba e a sua atuação enquanto médico podem ser algumas possibilidades.

\section{$\operatorname{son} 2$}

${ }^{45}$ ODILON, Camillo de Hollanda..., p. 122. 


\section{RESUMO}

Este texto analisa alguns aspectos das redes de sociabilidade e da atuação de Francisco Camillo de Hollanda na Parahyba, médico, coronel do exército e político, entre os anos de 1916 e 1920, período da vigência do seu mandato enquanto presidente do estado. Aspectos relacionados à organização política local que antecedeu a candidatura de Camillo de Hollanda, as redes que se firmaram $e$ as principais ações em sua gestão, são discutidas. Imbuído dos preceitos modernos e guiado pelos ideais sanitaristas, esse governo desenvolveu uma proposta de gestão do estado baseada nesse ideário. Sobressaíram-se mudanças na arquitetura da capital - abertura e alargamento de ruas, construção e revitalização de praças $e$ prédios públicos, iniciativas preocupadas por inserir o país na modernidade sob os ideais de higiene, beleza e progresso. Para realizar a investigação, utilizamos como fontes algumas matérias dos jornais da época, cartas, livros de História da Paraíba e mensagens presidenciais. Rever as relações dos sujeitos em torno de uma candidatura política nos ajuda a entender discursos, predileções $e$ disputas que reverberaram nas ações empreendidas $e$, certamente, influenciaram os rumos do desenvolvimento do estado da Parahyba.

Palavras Chave: Camillo de Hollanda; Parahyba; Redes de Sociabilidade.

Artigo recebido em 10 set. 2016.

Aprovado em 16 mai. 2018.
ABSTRACT
The text analyzes some aspects of the networks of sociability and the acting of Francisco Camillo de Hollanda in Parahyba. Camillo de Hollanda was a doctor, army colonel and politician. Between the years 1916 and 1920 he was president of the state. The networks were strengthened and stocks in Camillo de Holanda management, even than related to local political organization prior to her application as President of the State, when the networks were discussed. Imbued of modern precepts and guided by sanitarian ideals, his government developed a state management proposal based on this ideas. In his management was highlighted changes in architecture of the capital - opening and widening of streets, construction and revitalization of squares and public buildings, concerned initiatives for entering the country in modern times under the ideals of hygiene, beauty and progress. To conduct the research, was used as sources some matters of newspapers of the time, letters, books of history of Paraiba and presidential messages. Review the relations of the subjects around a policy application helps us to understand discourses, predilections and disputes that reverberated in the actions undertaken and certainly influenced the direction of development of the state of Parahyba.

Keywords: Camillo de Hollanda; Parahyba; Networks of sociability. 